\title{
Innovative geometric design improves the resistance of simple metal / metal lap joint
}

\author{
Mehadjia Bezzerrouki, Kouider Madani, Abderrahmane Sahli \\ University of Djillali Liabes, LMPM Laboratory, Sidi Bel Abbes, Algeria \\ m_bezzerrouki@yahoo.fr,koumad10@yahoo.fr,sabliabderahmen@yahoo.fr
}

Sébastien Touzain, Stéphanie Mallarino

University of La Rochelle, LASIE Laboratory, La Rochelle, France

sebastien.touzain@univ-lr.fr,stephanie.mallarino@univ-lr.fr

\begin{abstract}
Bonded assemblies are widely used in many industrial sectors mainly in the aerospace field. Many researches in these domains are focused on evaluating the stresses in the adhesive layer in order to achieve maximum strength and long service life. Factors that affect joint design are the mechanical and physical properties of the adhesive and the substrate. The reduction of stress concentration at the edges of the adhesive provides the strength of the adhesive layer. Our work fits in this context, based on the ASTM D1002 standard. The innovative idea of this paper is to bring geometric improvements to an assembly system type Aluminum/Aluminum 2024-T3 bonded with an adhesive ADEKIT A-140. The analysis of the stress distribution is performed by the three-dimensional finite element method using the ABAQUS calculation code. The geometric improvements presented in this work are beneficial and the results show a good reduction of the stress concentration along overlap length.
\end{abstract}

KEYwORDS. Single lap joint; Adhesive; Stresses; Overlap length.

\section{OPEN ACCESS}

Citation: Bezzerrouki, M., Madani, K., Sahli, A., Touzain, S., Mallarino, S., Innovative geometric design improves the resistance of simple metal/metal lap joint, Frattura ed Integrità Strutturale, 48 (2019) 491-503.

Received: 02.01 .2019

Accepted: 12.02 .2019

Published: 01.04.2019

Copyright: (C) 2019 This is an open access article under the terms of the CC-BY 4.0, which permits unrestricted use, distribution, and reproduction in any medium, provided the original author and source are credited.

\section{INTRODUCTION}

7 he principal aims of adhesive bond are to ensure a uniform distribution of stress along overlap length and transmit a maximum of them to minimize a stress concentration which causes damage [1]. Structural adhesive are strong, with a specifics characterizations which respond for the needs of different fields. The study of the influence of shear and peel stresses are very interesting in the fracture mechanics. The ASTM is an international standards organization that prepares and produces technical standards for materials, systems and products, it's developed for testing and 
classifying different Materials used normalized specimen. The ASTM D1002 [2] is used for testing shear stress strength of adhesive for single lap joint made of two normalize plates adhesively bonded under tensile load.

One presents here a brief outline of previous related works in the same domain. Goland and Reissner worked on the behavior of flexible adhesive using a normal stress [3]. Hart-Smith studied the shear and peel stresses distributions and gives a simplification for uncoupling shear and peel stresses [4]. He also developed solutions for stepping a single lap joint [5]. Bigwood and Crocombe [6] presented general elastic, shear and peel analysis for single lap joint using finite element analysis. Chiu and Jones [7] applied a finite element method to study a shear stress using a thick adherend test for a single and a symmetrical double lap joint. Pereira and Morais [8] conducted an experimental study using a double cantilever beam tests for single and double lap joints measured the critical strain energy-release rate and numerical one with finite element analysis using Abaqus code to explain a strength behavior and peel stresses at the edges of overlap area.

Setoodeh, A. R and al. [9] used numerical and analytical methods for double lap joints to calculate peel stress using crack closure integral method and J-integral approach. Nunes, S.L.S and al. [10] a numerical analysis was used to compares the tensile performance of different chosen adhesives for single and double-lap joints by varying the overlap length to express normal and shear stresses over adhesive thickness and the cohesive zone modeling approach is introduced to estimate the joint strength.

Recently, several studies have been made to try to reduce the stress concentration at the edges of the adhesive by the geometric modification of the edges of the plate by bevelling and or bead of the adhesive $[11,12]$ or by the combination of two modifications. Others have tried to improve the overlap length by geometrical modification for the adhesive and adherends edge such a waved, beveled or notched which presented a significant decrease in peel and shear stresses and ameliorate the quality and the durability of the structural adhesive joints [13], as well as the assembly of composite materials, attempts have been made to introduce hybrid composite materials and to change fiber orientations in the different adhesive layers. Madani, K. and al. [14] studies the effect of the geometry of the edge adhesive and adherend on reducing Von Mises, peel and shear stresses in the adhesive layer, several forms were considered namely bead of adhesive, internal and external beveling of the plate and the combination of an adhesive bead and beveling of the plate [15].

Our work fits in this context; the aim of this study is to improve the bonding techniques by introducing geometric modifications on ASTM-D1002 single-lap-joint making with 2024-T3 Aluminum specimens bonded with ADEKIT A140 adhesive. Two modifications are made to the single-lap-joint ASTM-D1002, the first is a reduction of thicknesses of plates along overlap length and the second one is to apply a reduction for only one plate for the assembly. The specimens were simulated numerically by the three-dimensional finite element method using the ABAQUS calculation software. The results clearly show that these two modifications bring about a considerable reduction of the stresses at the edge and the depth of the adhesive.

\section{GEOMETRICAL MODEL AND MECHANICAL PROPERTIES}

$\mathrm{O}$ ne considers an assembly of two 2024-T3 Aluminum plates bonded with ADEKIT A-140 adhesive. The basic geometric model is the ASTM D1002 single-lap-joint. The dimensions of the different substrates of the ASTM D1002 single-lap-joint without modification are shown in Fig. 1 and it is called in this paper: Model 1. The fixations localized are gives at grips areas and the stress are applied at one side along $\mathrm{X}$ axis using variable values.
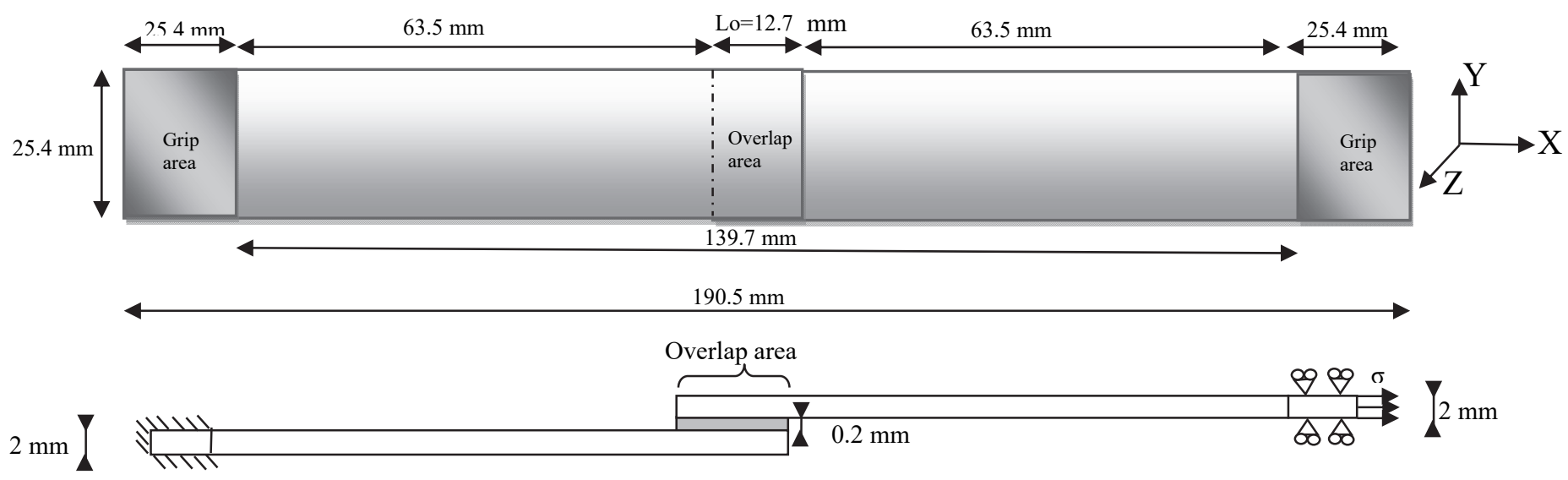

Figure 1: Basic geometrical model ASTM D1002 (Model 1). 
ADEKIT A-140 Adhesive presents a high mechanical performance and is used in several industrial sectors, in aeronautics. Among these advantages:

- Excellent mechanical and thermal performances up to $100^{\circ} \mathrm{C}$

- Excellent strength to dynamic loads (vibrations and impacts)

- Product adapted to stringent ageing and aggressive environments

The mechanical properties of the various substrates are taken from the tensile curves of aluminum plates and mass specimens of adhesive Adekit A-140 which are represented in Fig. 2, [16].

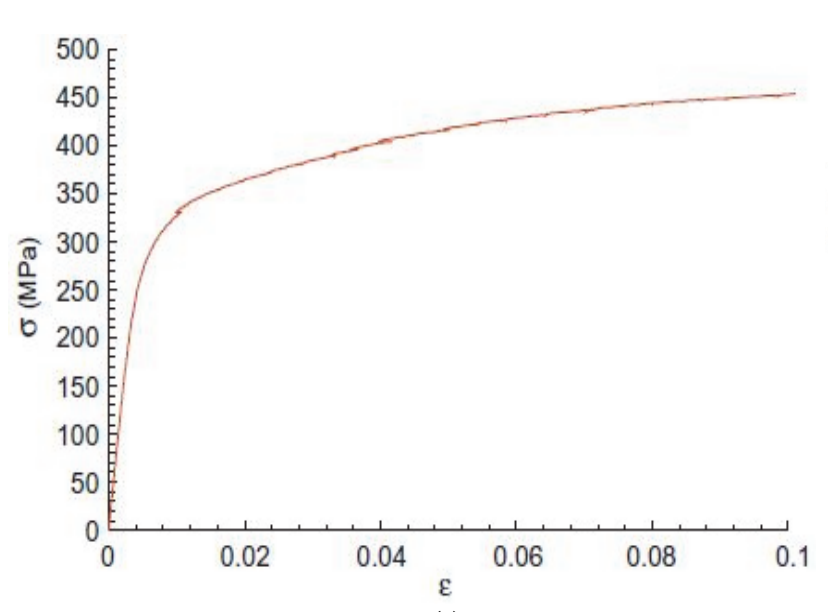

(a)

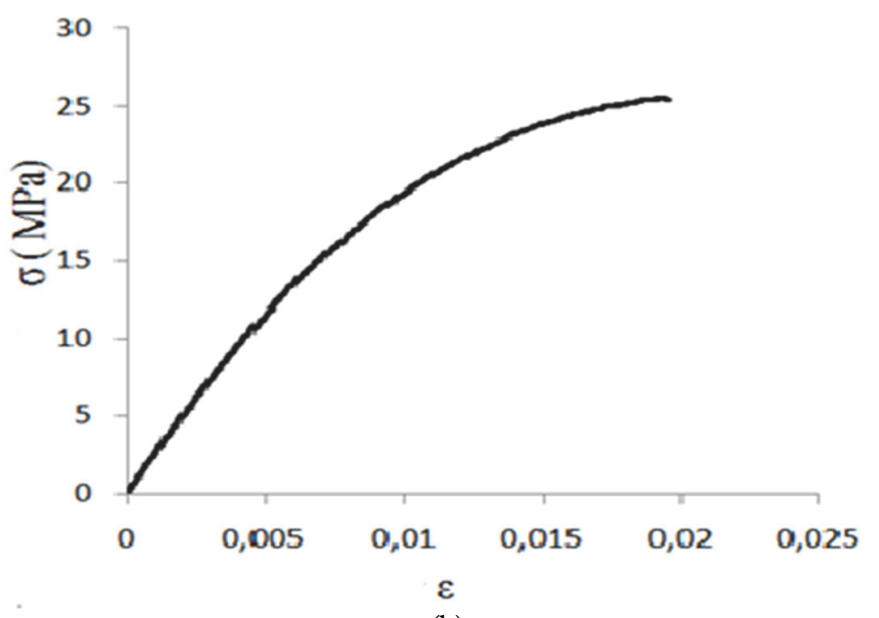

(b)

Figure 2: Stress/strain curves: a) Aluminum plate 2024-T3; b) Adhesive Adekit A-140 [16].

\begin{tabular}{cccc}
\hline Materials & $\begin{array}{c}\text { E: Young Modulus } \\
(\mathrm{GPa})\end{array}$ & $\begin{array}{c}\text { G: Shear modulus } \\
(\mathrm{GPa})\end{array}$ & v: Poisson coefficient \\
Aluminum: 2024-T3 & 69 & 36.92 & 0.3 \\
Adhesive: Adekit & 2.690 & 0.99 & 0.3 \\
A-140 & & & \\
\hline
\end{tabular}

Table 1: Elastic properties of the Aluminum plate and the adhesive [16].

The adhesive bonded joints have several advantages compared to the mechanical assemblies (riveting and bolting) which ensures uniform stress distribution and transfer over the bonded surface following the absence of holes and avoids overweight bolts but it is necessary to prevent the stress concentration at the edge and the environment effects (temperature, moisture) which causes a degradation of their mechanical properties and which will consequently have a bad transfer of load and thus a disband.

For our study, we tried to present a method for the bonding of the aluminum plates on the damaged surface; this method consists to remove a material from the aluminum plate over overlap area with a thickness of $0.2 \mathrm{~mm}$ on a single plate, which illustrated at assembly named: Model 2, as shown in the Fig. 3. And the second modification is to remove a thickness of $0.1 \mathrm{~mm}$ of aluminum material from each plate which represented at assembly called: Model 3, as shown in the Fig. 4. This procedure covers the adhesive layer which can protect the assembly from the aging following the effect of temperature and moisture.

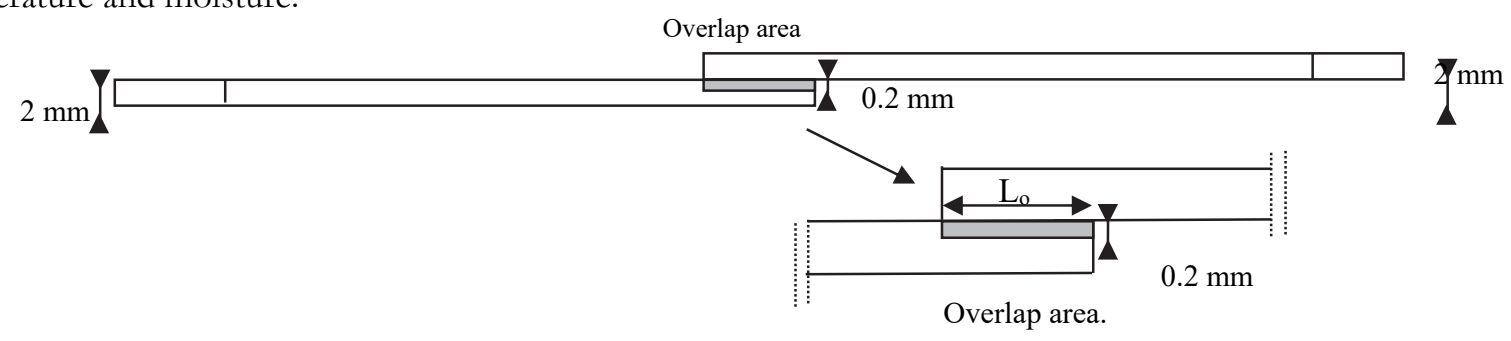

Figure 3: Model 2: ASTM D1002 modified (reduction of $0.2 \mathrm{~mm}$ for one plate) 


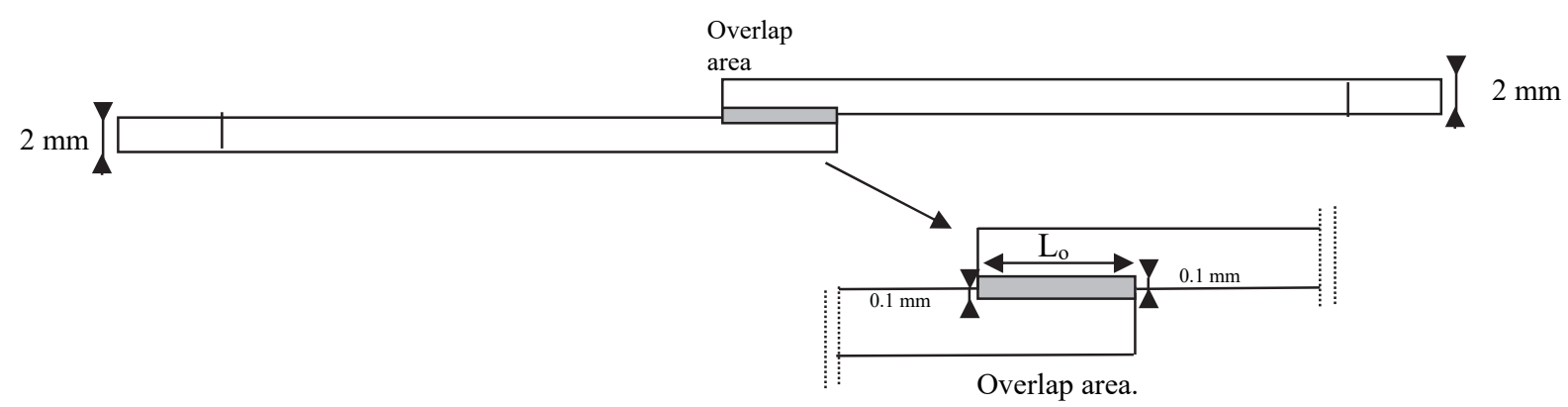

Figure 4: Model 3: ASTM D1002 modified (reduction of $0.1 \mathrm{~mm}$ for both of plates).

\section{FINITES ELEMENTS MODELS}

7 he models are simulated with a three dimensional finite element method analysis using Abaqus software [17]. A refined mesh is presented at the adhesive layer and plates to determine the maximum stresses which are located at the adhesive interface / adheres to the free edge. Indeed, the refinement of the mesh is of great importance for the analysis of the structure. The linear elements (C3D8R) are used for the mesh of all parts of the models studies. The number of elements over parts of Aluminum plate and the Adhesive layer are respectively 14240 and 1275 for the model 1, 16167 and 1275 for model 2 and 3. The Fig. 5 shows the detail of the meshed models.

Each layer is considered as an individual three-dimensional structure under a state of plane-stress and can be connected with adhesive bonds. The Adhesive layer is homogeneous, elastoplastic, isotropic and deforms under shear and peel stresses.

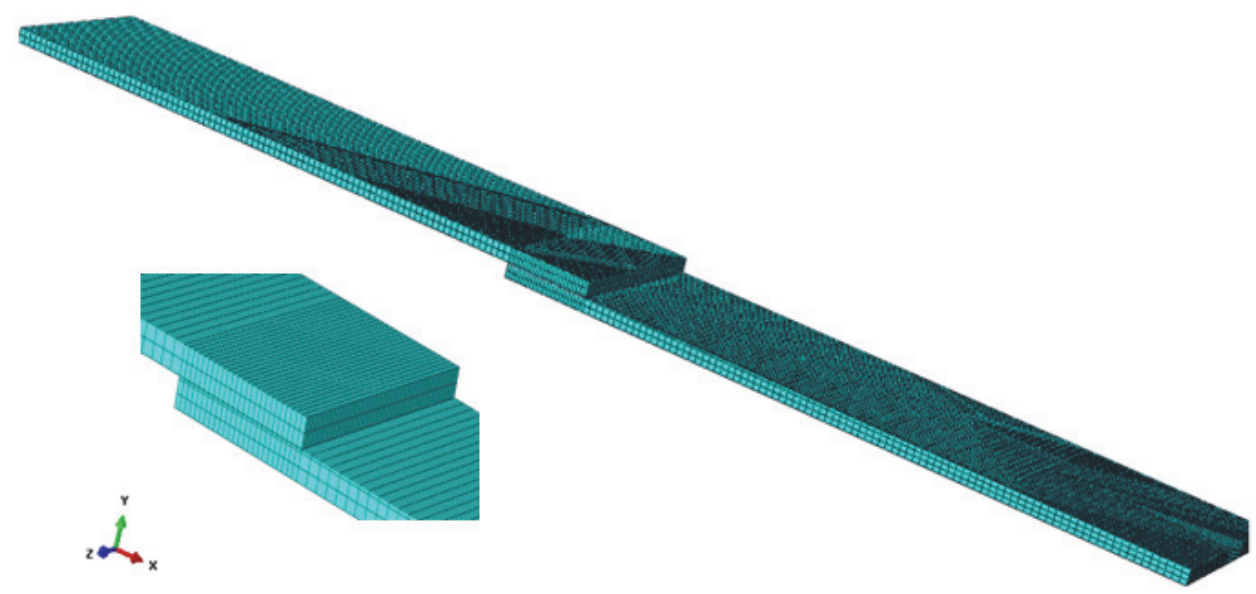

Figure 5: Mesh of the single-lap-joint and the detail at the overlap joint.

In the finite element model the nodes are common between the Aluminum plate and the adhesive layer so that there is a continuity of deformation and stress. This technique of the three layers modelling was used by Naboulsi and Mall [18]. The advantage of modelling the adhesive is to provide a continuous body to be able to capture the characteristics of the adhesive which are required for considering the progressive damage, heating effects, a nonlinear behavior of material, etc.

\section{RESULTS AND ANALYSIS}

7 he overlap length is an important parameter in the strength of the assembly, for the ASTM D1002 there are a small overlap length compared to the length of plates and therefore a large load transfer through the adhesive layer. 
The analysis of the stress distribution in the bonded assemblies is essential in order to predict the level of stress intensity for each substrate. Almost all the applied load will be transmitted to the adhesive which is the weak link of the structure seen these weak mechanical properties comparing to those of the plates. The adhesive will be subjected to a set of stresses, mainly the shear and peel stresses caused by the non-linearity of the two forces.

One exposed the Fig. 6 to explain the difference of stresses between the zones A and B. The stress distribution is not symmetrical because the two edges of the adhesive are not included at the same zone of the plate. Fig. $6 a$ shows an example of Von-Mises stresses distribution for an applied stress of $20 \mathrm{MPa}$ for Model 1.

The stress distribution in the adhesive layer for the single lap joint is not homogeneous. In our study the stress distribution was determined along the $\mathrm{AB}$ segment on the adhesive / plate contact area represented in the Fig. 6b. Noting that the points $\mathrm{A}$ and $\mathrm{B}$ represented the zones $\mathrm{A}$ and $\mathrm{B}$ respectively. The point $\mathrm{A}$ is on the free side at the edge of the adhesive and the plate, so we have high stresses due to the edge effect. On the other side, the point B is on the plate and at the limit only of the adhesive where the stresses are lower compared to the point $\mathrm{A}$.

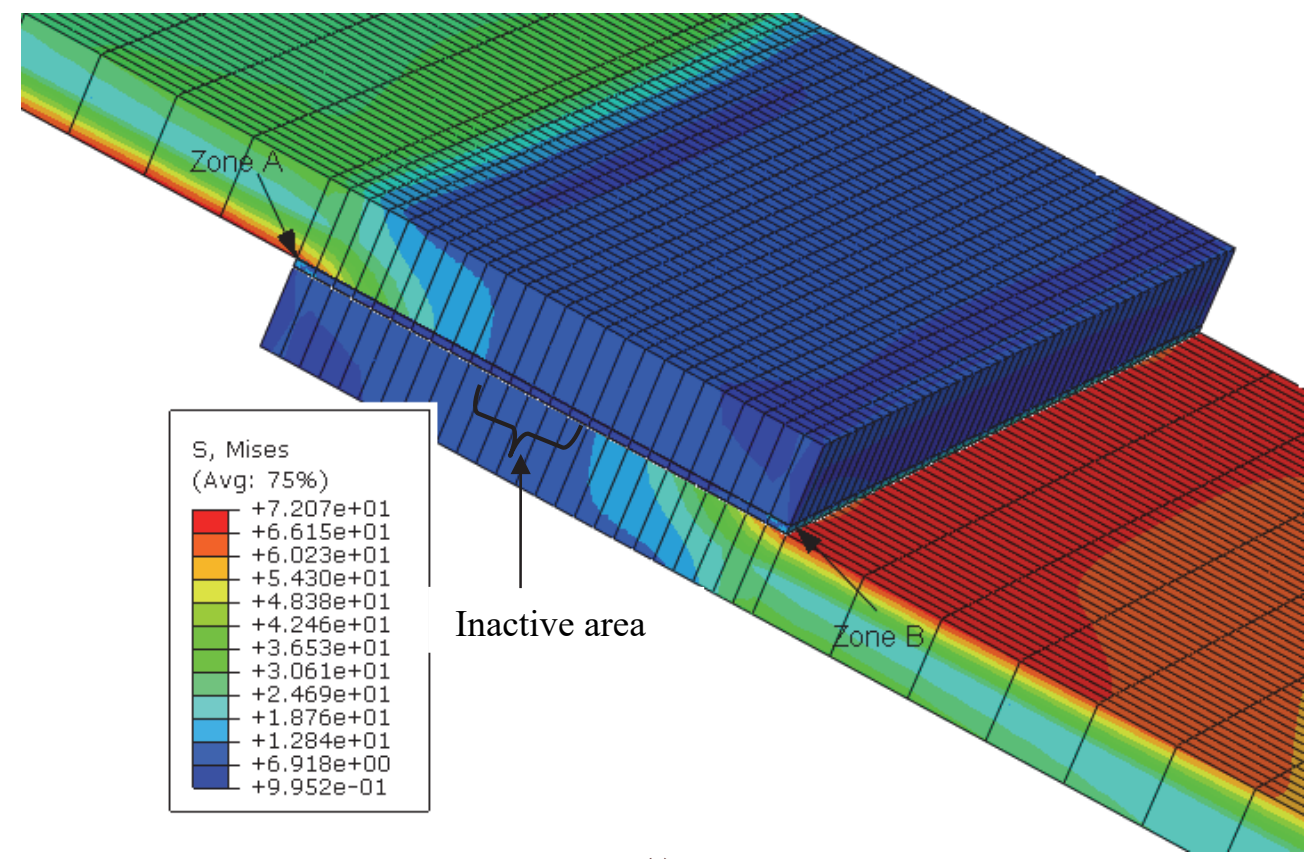

(a)

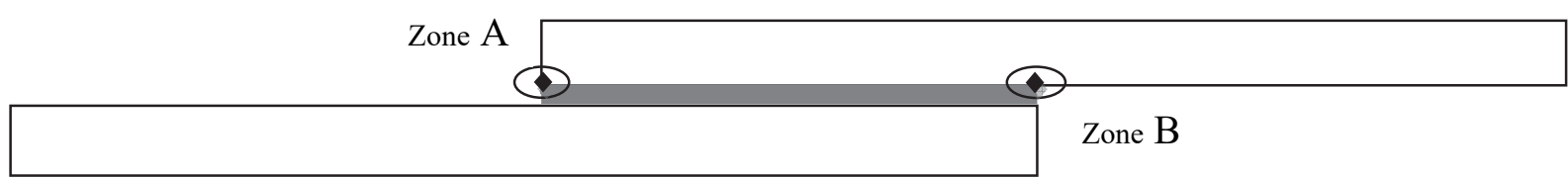

(b)

Figure 6 : (a) Von-Mises stresses distribution, (b) Representation of zones A et B.

\section{Study of the stress distribution for model 1}

One knows that the area stressed in the adhesive increase proportionally with applied stress and it is the same for the shearing and peeling stresses. Fig. 7 shows the variation of Von-Mises stress, shear and peel stresses at the adhesive layer. One note that shear stresses remain almost low than Von-Mises and peel stresses.

We clearly notice that whatever the value of the applied stress is the stress concentrations are localized at the edge adhesive layer. The depth of the adhesive remains inactive for low stress applied. An applied stress of $10 \mathrm{MPa}$ generates a stress of $15 \mathrm{MPa}$ in the adhesive. While the increase of the stress applied to $20 \mathrm{MPa}$ generates almost $30 \mathrm{MPa}$ what causes a degradation of the adhesive and makes work in its field of rupture.

The bending moment caused by the nonlinearity of the forces causes high values of peel stresses, since the overlap length is minimal comparing to the lengths of the plates. 


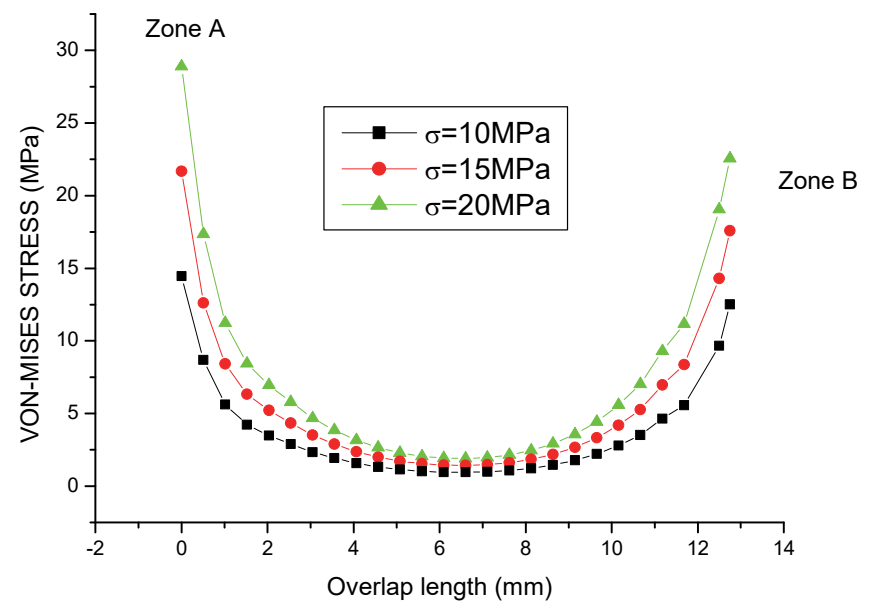

(a)

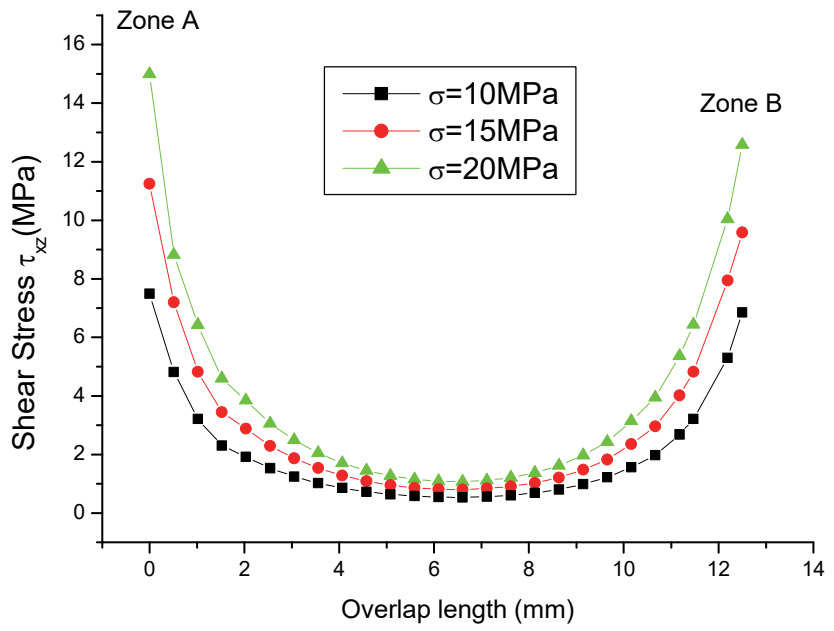

(b)

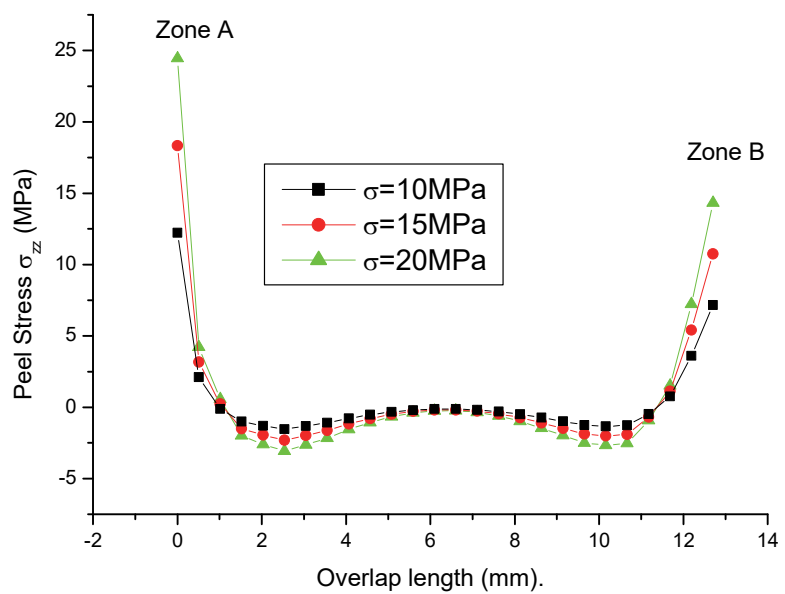

(c)

Figure 7: Variation of a) Von-Mises, b) Shear and c) Peel stresses in the adhesive layer along the overlap length (case of Model 1). 


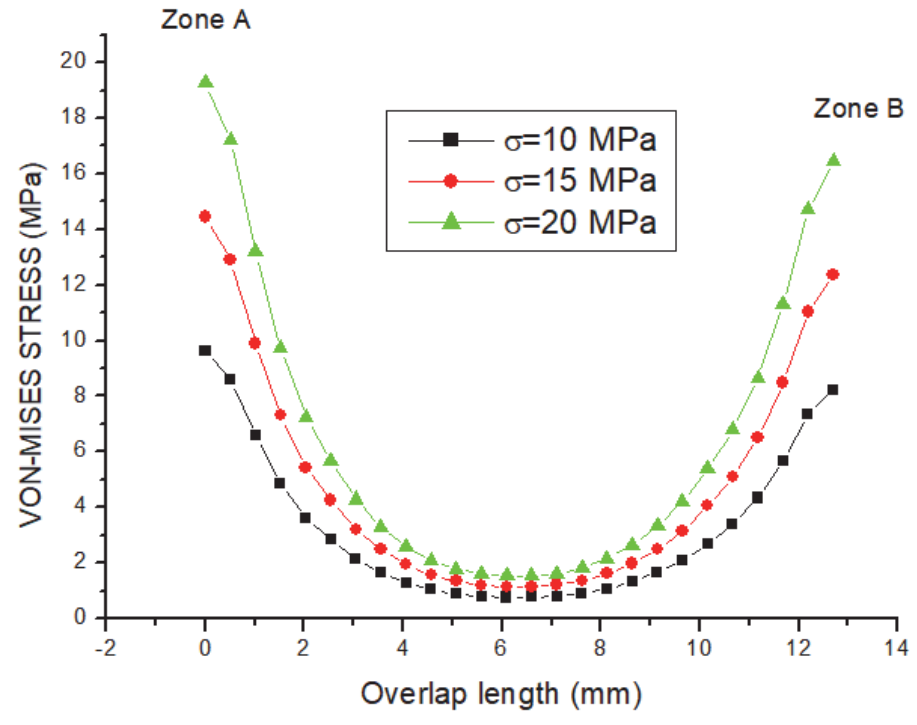

(a)
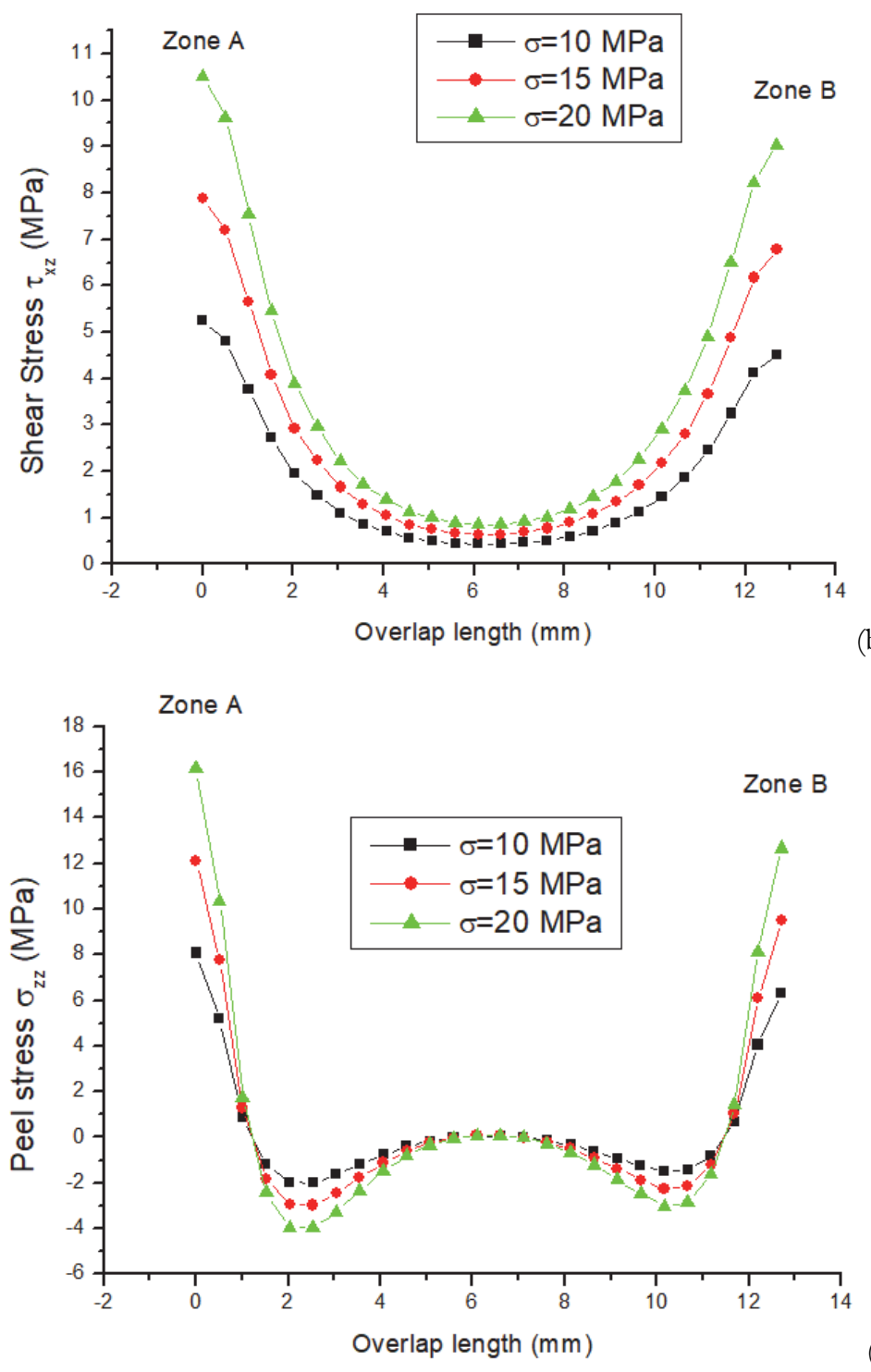

(c)

Figure 8: Variation of a) Von-Mises, b) Shear and c) Peel stresses in the adhesive layer along the overlap length (case of Model 2). 
Study of the stress distribution for model 2

The Fig. 8 represents the variation of the stresses in the adhesive layer after modification in one of the two plates by removal of the material with a thickness of $0.2 \mathrm{~mm}$ so that the adhesive is entirely placed in one of the two plates, this will allow the adhesive to be exposed on one side to temperature and humidity.

This method reduces the stresses at one of the two edges by reducing the bending moment. Likewise, the increase in the applied stress increases the value of the various stresses in the adhesive layer. The depth of the adhesive will be less stressed comparing to the case of model1.

The shear stress becomes a little weak in the adhesive and whatever the value of the stress applied at the edge and the core of the adhesive. Likewise for peeling stresses, the values become weaker and the risk of peeling becomes negligible even for high stresses. Adding that as the first model the distribution of stresses remain unsymmetrical.

\section{Study of the stress distribution for model 3}

The Fig. 9 shows the variation of different stresses for the third model. It is clearly seen that the modification made to the two plates by removing the $0.1 \mathrm{~mm}$ material on each side of the plates has a considerable reduction in the various stresses at the edge and at the depth. In addition, symmetry is present in the stress distribution at the adhesive layer. We also note that the increase in the various stresses (Von-Mises, shearing and peeling) is low especially compared to model 1. It is concluded that the risk of separation is almost negligible in model 3 .

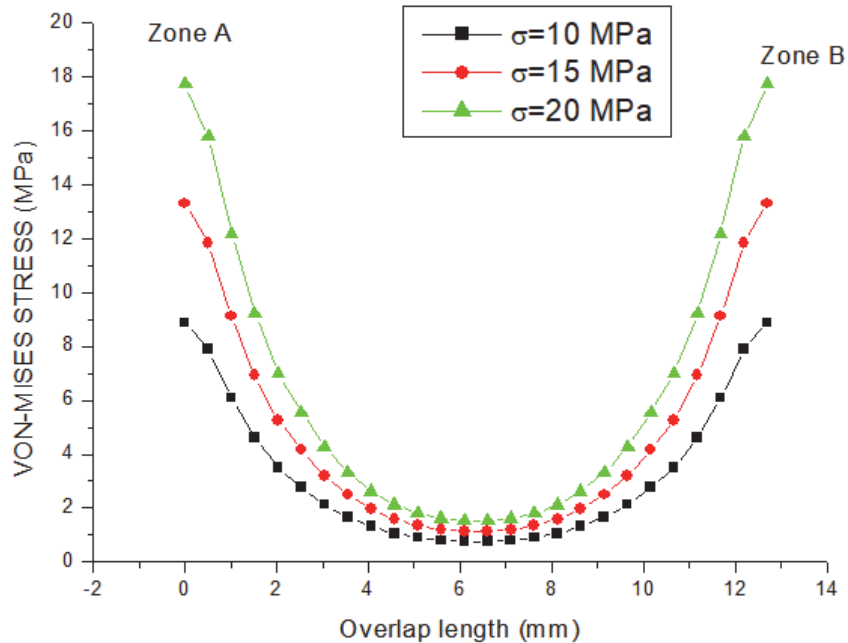

(a)

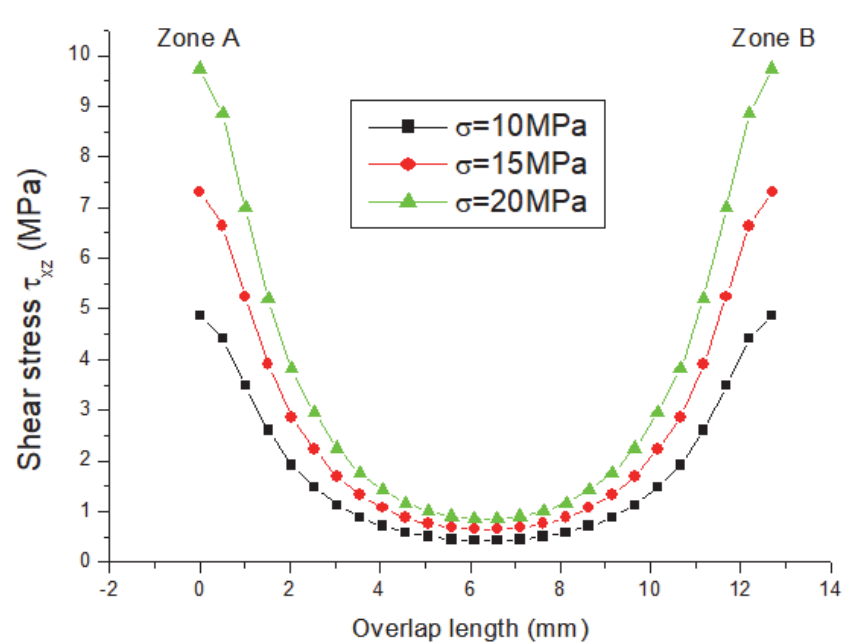

(b)

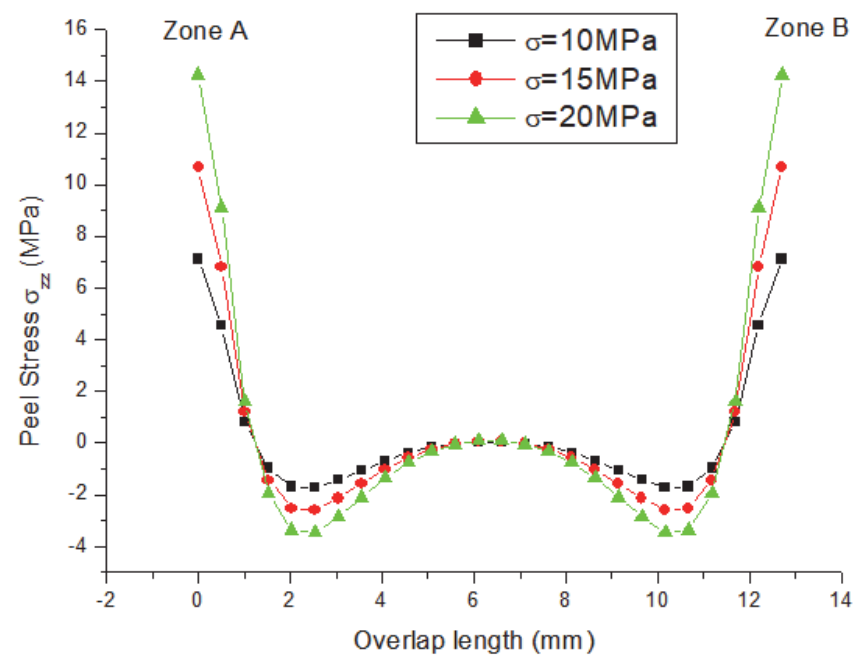

(c)

Figure 9: Variation of a) Von-Mises, b) Shear and c) Peel stresses in the adhesive layer along the overlap length (case of Model 3). 
Comparison of stresses at edge and depth of assembly along overlap length for the 3 models

In order to clearly present the effect of the modifications made to the plates under the variation of the stresses, Figs. 10 and 11 present the comparisons of the stresses at the edge and the depth of the adhesive.

It is clear that increasing the applied stress considerably increases the various stresses at the edges. The percentage increase varies depending on the applied stress and the model used. One remark that; the first model has the highest rate for the different stresses in the adhesive layer and the lowest values are noted for the model 3.

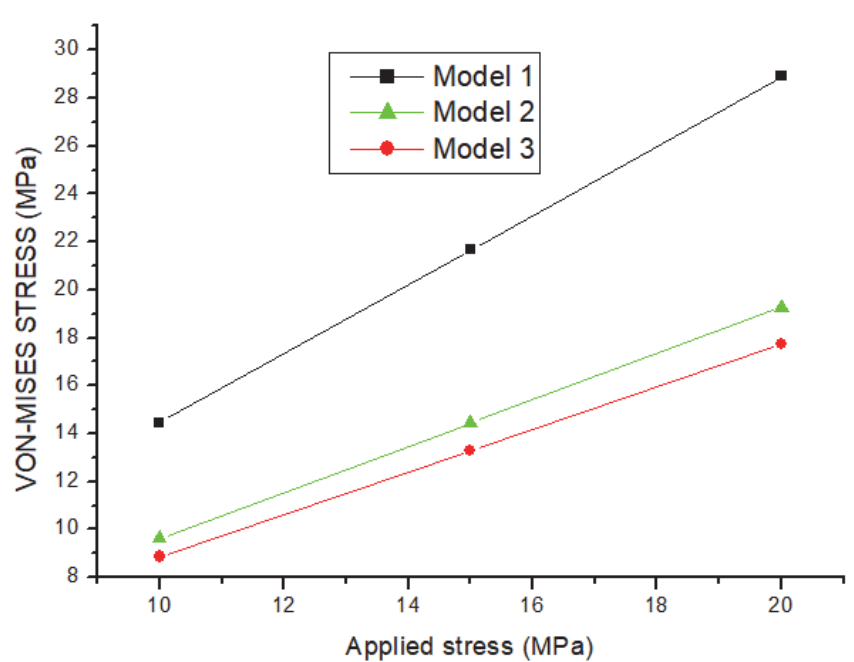

(a)

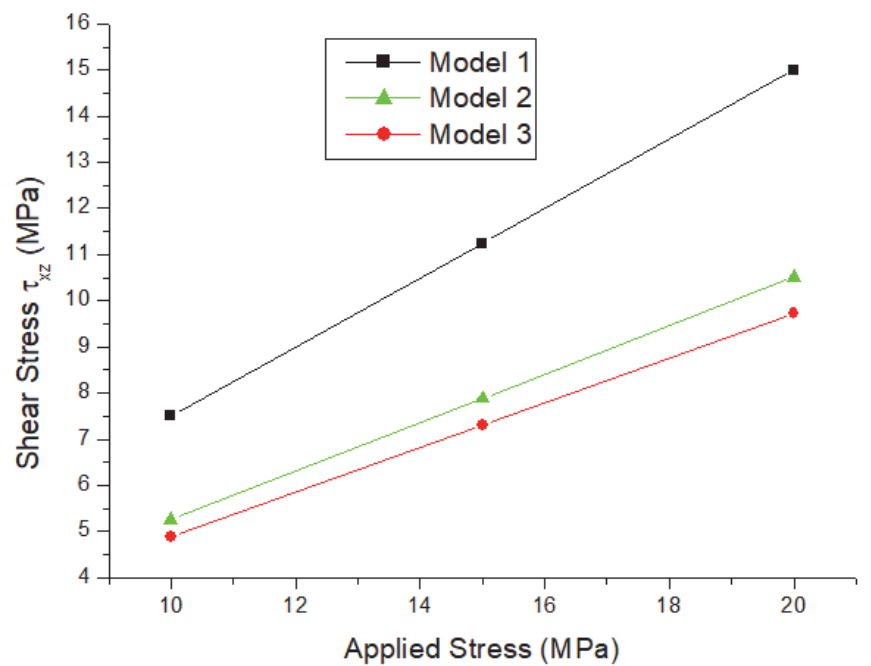

(b)

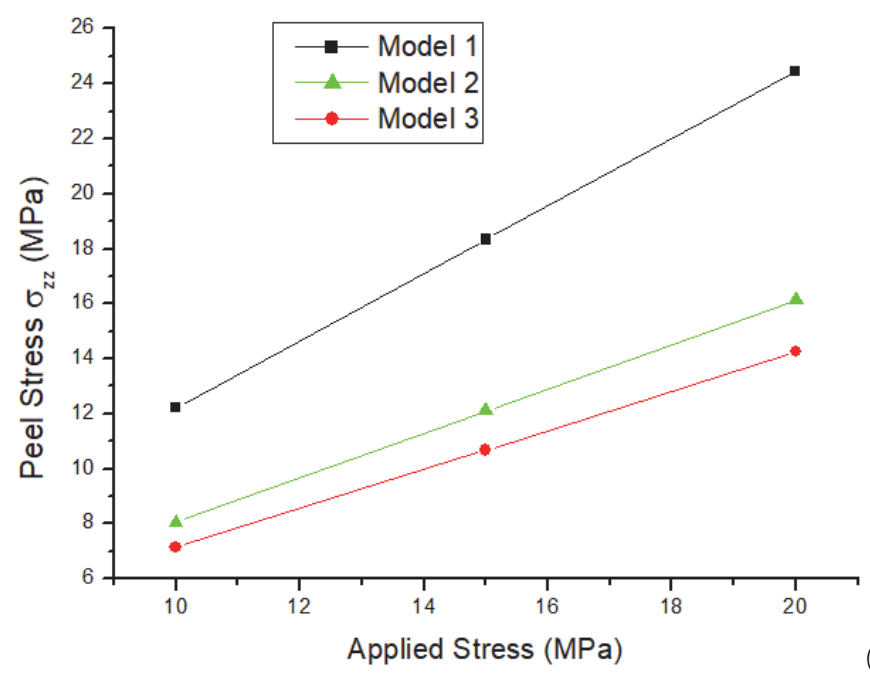

Figure 10: Comparison of the stresses (a) -Von-Mises, (b) -Shearing and (c) - Peeling at edge for the 3 models of assembly according to the stresses applied.

Analyzing now the Fig. 11 which gives the comparisons of the stresses inside the adhesive layer for the 3 models. It is noted that the stresses on the depths of the adhesive layers have low augmentation with the increase of applied stresses. For models 2 and 3 the stress curves coincide for the three types of stresses.

\section{Comparison of inactive lengths}

In single-layer assemblies, adhesive is the weakest link in the structure where its mechanical properties are lower than those of the two plates and therefore the risk of cracking or separation of the plates is high.

Most research in this area is aimed at reducing edge stresses and working the central part of the adhesive, which in most cases remains inactive. 
The purpose of this document is to modify the thickness of the two plates at the overlap length to minimize the concentration of stresses at the free edges that cause deflection and to try to work the central part of the adhesive. For this purpose, the ratio of the inactive length of the adhesive to the total length of the adhesive was represented to illustrate the effect of this geometric modification on the thickness of the two plates. Thus introducing an idea of the comparison of inactive lengths that represent the variation of the inside length of the adhesive which is the safety zone to ensure the strength and adhesion of the assembly. The inactive length is shown in Fig. 6a.

The Fig. 12 represents the variation of the ratio of the inactive length and the overlap length $\left(\mathrm{L}_{\text {inactive }} / \mathrm{L}_{0}\right)$ for the different stresses (Von-Mises, shear and peel). It is noted that the increase in the applied stresses surely generates a decrease of the ratio $\mathrm{L}_{\text {inactive }} / \mathrm{L}_{0}$ but the difference remains weak comparing the three models which confirms the effectiveness of models 2 and 3. And on another side, one conclude that the changes made to the overlap part in the plates cause stresses in the entire overlap area and therefore the depth of the adhesive becomes active, which reduces the stresses at the edges.

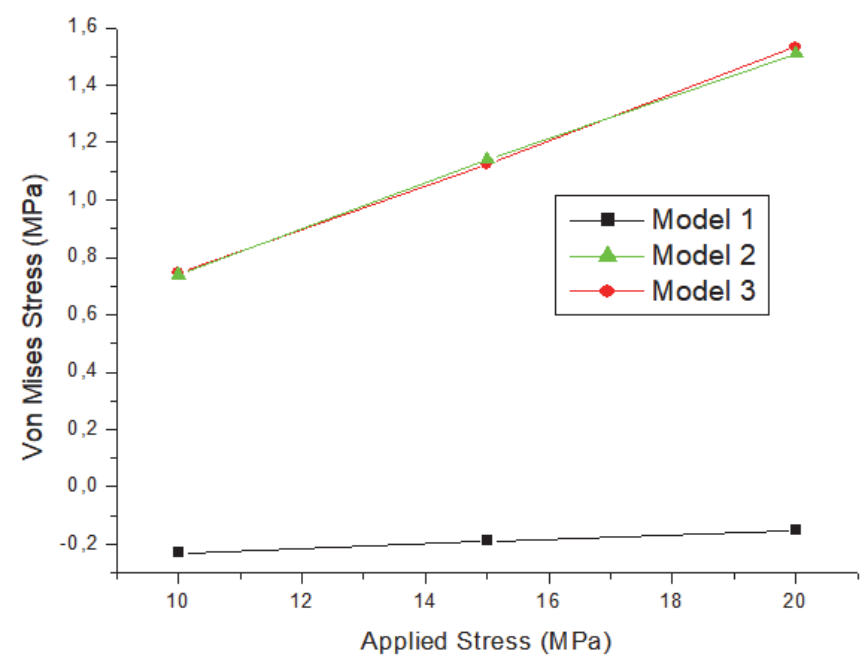

(a)

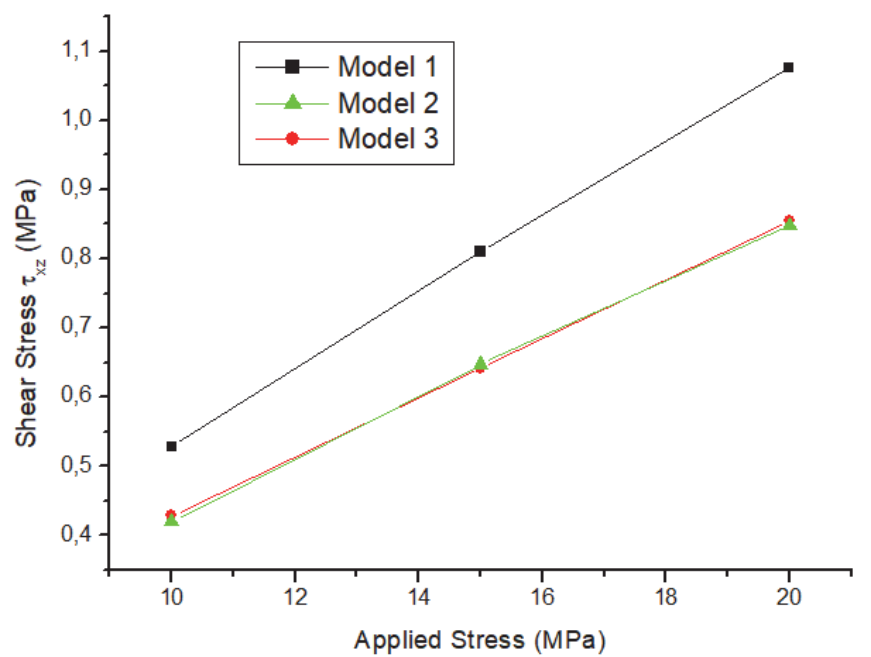

(b)

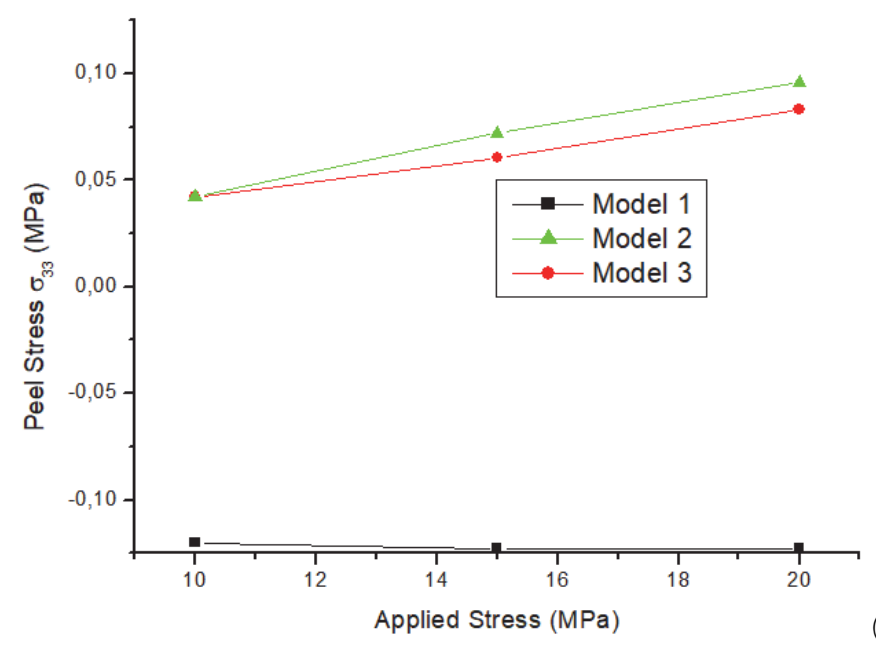

(c)

Figure 11: Comparison of the stresses (a) -Von-Mises, (b) -Shearing and (c) - Peeling to the depths for the 3 models of assembly according to the stresses applied.

\section{CONCLUSION}

I n this study, the recapitulation of comparison of results for the models study gives following conclusions:

At the edges of the adhesive layer, the model 01 has the highest rate for the different stresses (Von-Mises, shear and peel), and the lowest values of this stresses are noted for the model 3 which attest the efficiency of the modification affected to the single-lap-joint. 


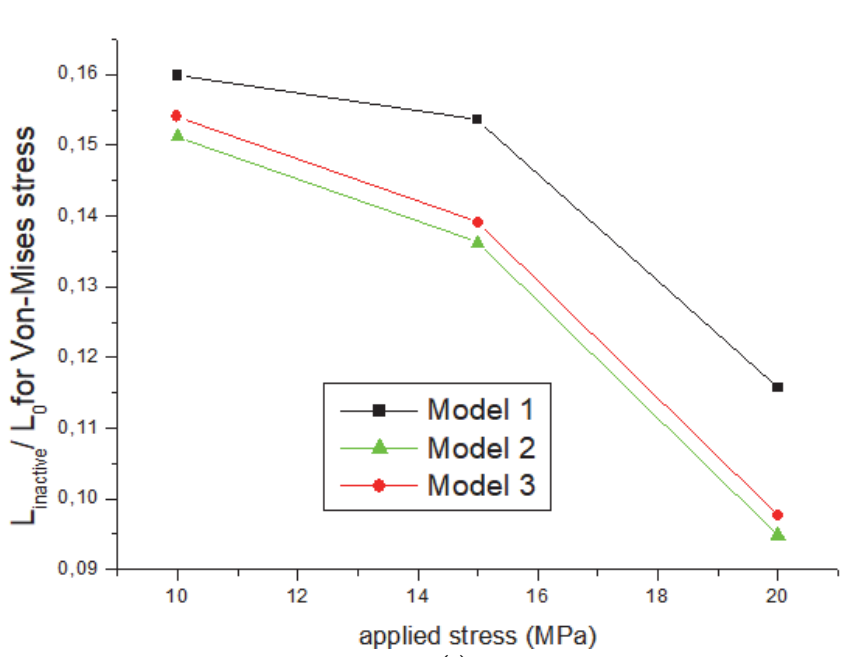

(a)

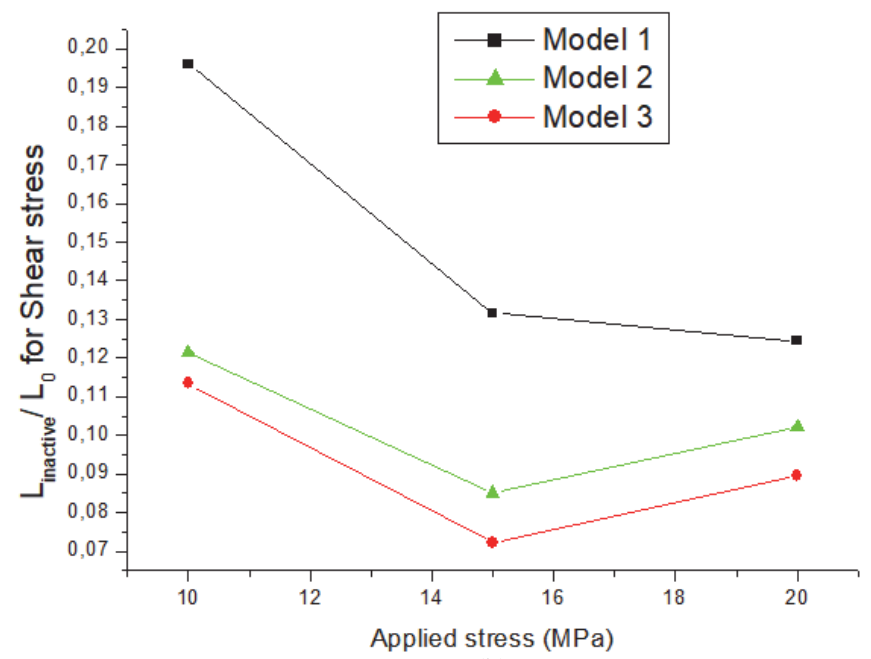

(b)

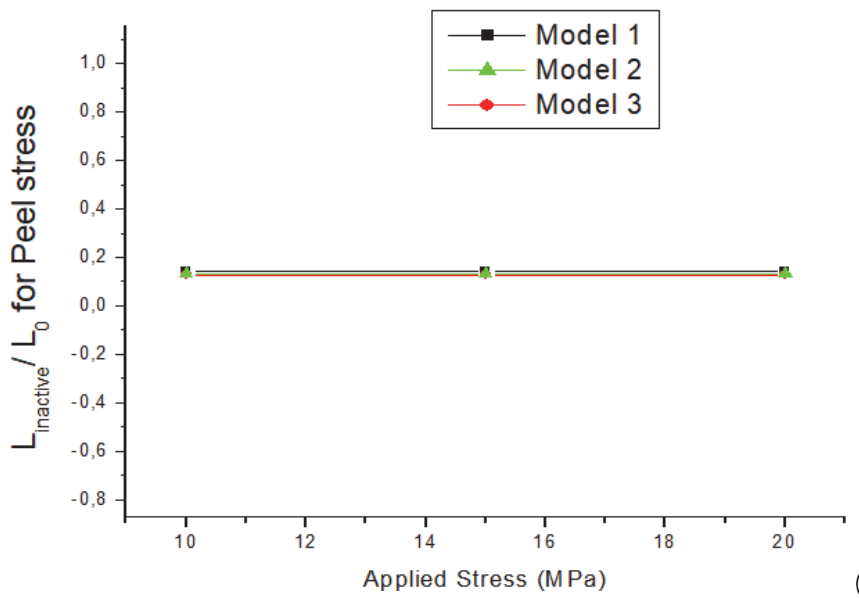

(c)

Figure 12: Comparison of the ratio Linactive / L0 according to the stresses applied of the 3 models for the stresses of: (a) - VonMises, (b) - Shearing and (c) - Peeling.

- At the depth of the adhesive layer, different stresses analyzed have low augmentation with the increase of stresses studied. Noting also that a same behaviors for models 2 and 3 for the three types of stresses.

- For the comparison of inactive length, the increase in the applied stresses surely generates a decrease of the ratio $\mathrm{L}_{\text {inactive }} / \mathrm{L}_{0}$ but the difference remains weak comparing the three models which confirms the effectiveness of models 2 and 3 .

- The modification made to the plate considerably reduces the stresses at the edge of the adhesive and therefore makes the depth of the adhesive work, which balances the stresses along overlap length.

\section{REFERENCES}

[1] Baker, A., Rose, F., Jones, R. (2002). Advances in the bonded composite repair of metallic aircraft structures. 1-2. Elsevier.

[2] ASTM Standards (1999). Standard Test Method for Apparent Shear Strength of Single-Lap-Joint Adhesively Bonded Metal Specimens by Tension Loading (metal-to-metal).

https://www.admet.com/how-to-perform-an-adhesive-lap-joint-shear-strength-test-astm-d1002/

[3] Goland, M. and Reissner, E. (1944). J. Appl. Mech., (11), pp. A17-A24.

[4] Hart-Smith, L. J. (1973). Technical Report NASA CR 112236, Douglas Aircraft Company 
[5] Hart-Smith, L. J. (1973). Technical Report NASA CR 112237, Douglas Aircraft Company

[6] Bigwood, D. A. and Crocombe, A. D. (1989). Elastic analysis and engineering design formulae for bonded joints, J. Adhes. Adhes., (9), pp. 229-242, DOI:10.1016/0143-7496(89)90066-3

[7] Chiu, W. K. and Jones, R. (1992). Numerical study of adhesively bonded lap joints, J. Adhes. Adhes., (12), pp. 219225, DOI: 10.1016/0143-7496(92)90057-3.

[8] Pereira, A. B. and Morais, A. B. (2003). Strength of adhesively bonded stainless steel joints, J. Adhes. Adhes., (23), pp. 315-322, DOI: 10.1016/S0143-7496(03)00049-6.

[9] Setoodeh, A. R., Hadavinia, H., Biglari, F. R. and Nikbin, F. K. (2005). Comparison of Analytical, Numerical, and Experimental Methods in Deriving Fracture Toughness Properties of Adhesives Using Bonded Double Lap Joint Specimens, J. Adhes. Adhes., (81), pp. 529-553, DOI: 10.1080/00218460590944963.

[10] Nunes, S.L.S., Campilho, R.D.S.G., Da Silva F.J.M., De Sousa C.C.R.G., Fernandes T.A.B., Banea M.D., Da Silva L.M.F. (2015). Comparative failure assessment of single and double-lap joints with varying adhesive systems, The Journal of Adhesion, DOI:10.1080/00218464.2015.1103227.

[11] Elhannani, M., Madani, K., Chama, Z., Legrand, E., Touzain, S., \& Feaugas, X. (2017). Influence of the presence of defects on the adhesive layer for the single-lap bonded joint-Part II: Probabilistic assessment of the critical state. J. Aerosp. Sci. Technol., (63), pp . 372-386. DOI:10.1016/j.ast.2016.12.020.

[12] Elhannani, M., Madani, K., Legrand, E., Touzain, S., \& Feaugas, X. (2017). Numerical analysis of the effect of the presence, number and shape of bonding defect on the shear stresses distribution in an adhesive layer for the single-lap bonded joint; Part 1. J. Aerosp. Sci. Technol., (62), pp. 122-135. DOI:10.1016/j.ast.2016.11.024.

[13] Elhannani, M., Madani, K., Mokhtari, M., Touzain, S., Feaugas, X., Cohendoz, S. (2016). A new analytical approach for optimization design of adhesively bonded single-lap joint. J. Structural engineering and Mechanics, 59(2), pp. 313326. DOI : 10.12989/sem.2016.59.2.313.

[14] [14] Madani, K., Mokhtari, M., Belhouari, M., and Hannani, M. (2013). Effect of Modifying the Edges of the Adherends and the Adhesive on the Stress Distribution over the Width and Length of Recovery, Case of a Single Lap Joint J. of Mining, Metallurgy \& Mechanical Engineering (IJMMME). 1(4).

[15] Mokhtari, M., Madani, K., Belhouari, M., Touzain, S., Feaugas, X., Ratwani, M. (2013). Effects of composite adherend properties on stresses in double lap bonded joints. J. Materials and Design. (44), pp. 633-639, DOI:10.1016/j.matdes.2012.08.001.

[16] Madani, K., Touzain, S., Feaugas, X., Cohendouz, S., \& Ratwani, M. (2010). Experimental and numerical study of repair techniques for panels with geometrical discontinuities. Computational Materials Science, 48(1), pp. 83-93. DOI: $10.1016 /$ j.commatsci.2009.12.005

[17] ABAQUS/CAE, Ver 6.13 User's Manual, Hibbitt, Karlsson \& Sorensen, Inc.

[18] Naboulsi, S., Mall, S. (1996). Modeling of a cracked metallic structure with bonded composite patch using the three layers technique. J. Compos Struct; (35), pp. 295-308. 